\title{
Trust-based steering of large Engineering-to- Order offshore/onshore projects: is it possible?
}

\section{Dagrun Dvergsdal Trond Haga}

\begin{abstract}
:
The various traditions of socio-technical system design (STSD) emphasise different aspects of such systems, but the core relationship in the literature is between the use of technology and the set-up of organisations. Therefore, much attention has been paid to organisational issues, including work tasks, distributed responsibilities and processes. An organisation where tasks and responsibilities are distributed requires other forms of co-operation and clarification and, not least, that the actors trust each other. Nevertheless, trust has received little discussion in the STSD literature. This paper focuses on trust as a relational tool: the factors decisive for developing trust in a project management team established ad hoc to implement an offshore development project, how to develop trust in practice, and whether a focus on trust reduces the need for control measures. The purpose of systematic trust building is to develop team members who are, individually and as team members, able to deliver the results expected for their area and to support colleagues to do the same, thereby reducing the need for control measures. Trust building represents one way for the project manager to acquire control of the organisation, and it must therefore be better understood, starting with this question: how efficient are the various factors for the project manager in exercising power, i.e. ensuring control over project execution? The case in this paper illustrates the need to address trust and control in the set-up of a project management team, a focus which is also important for STSD in general.
\end{abstract}

Keywords: Socio-technical systems, team development, trust, task control, trustee-trustor, trust development, team process, fundamental principles 


\section{Introduction}

The offshore supplier industry is organised around projects, as much as other ETO supplier industries.28 When an offshore ETO contractor wins a project, a new project organisation has to be established. Parts of the new organisation may have been actively involved in the bidding phase, while other parts of the organisation have not. The offshore supply industry is an industry that delivers mass-produced tailor-made products, i.e., unique products with varying complexity, scope and execution time. Large projects can have an implementation time of four to five years, while smaller projects can be considerably shorter. Projects that the industry receives vary with regard to the scope division between the customer and the supplier, and between the supplier and the subcontractors. This means that the supplier must relate to different customers and different suppliers from project to project. Consequently, the project set-up varies from project to project, as does the project itself.

This set-up makes it impossible to retain fixed project management teams: they will vary from project to project. A team that works together on one project may thus be split up for the next project, and then may work together again later. However, it may often be many years before the team members are again part of the same project management team, which will be more or less like working with new colleagues. It may also be necessary for various reasons to include personnel from other companies. This constant change applies not only to the management team but also to the rest of the project organisation.

In order to manage a temporary project organisation, it is crucial from the project manager's perspective to quickly gain control of the actual execution of planned activities. Project managers can achieve control by using power and/or by using trust. All organisation is based on a form of balance between power and trust: if there is little trust, it may be replaced by control; if trust is high, control measures may be reduced.

This has been confirmed in the literature. Leaders may, by investing in building trust, increase the efficiency of the organisation (Barney and Hansen 1994). Consequently, control and control measures may be diminished considerably, as trust creates conditions for and mobilises both action and interaction (Sørhaug 1996). Trust is fundamentally a matter of confidence concerning an advantage or a gift that will be received in the future, and the confidence that this advantage or gift will be received without any claim to reciprocity. Building trust may consequently be perceived as a way of establishing control over the organisation and the work performed. To achieve the necessary control, different control agents may be used:

"For example, Bradach and Eccles (1989), who view trust as form for control, argue that managers direct subordinates by combining market-based, hierarchy-based and trust-based control mechanisms" (Long and Sitkin 2006:87).

From such a perspective, it is crucial for leaders to develop a clear understanding of factors that influence the ability to establish trust in the organisation, while at the same time providing them with control over the organisation and their delivery capacity. Likewise, trust is crucial for developing the individual team member or member of the organisation to be able to take on complex and challenging jobs, which is one of the basic prerequisites for STSD.

In an organisational setting, trust may be perceived as a way of gaining control over execution and results. It may arise through formal control mechanisms, such as contracts, incentives and surveillance, or through more relational mechanisms that touch emotions or values (Long and Sitkin 2006). However, trust may and will be perceived as a

28

ETO stands for engineering to order. Industry production may be diversified in accordance with the degree of standardization of the products, e.g., MTS (make to stock), MTA (make to Assembly), MTO (make to order) and ETO, the last of which produces the least standardized products. 
relational tool for achieving increased well-being and safety, and as a consequence, these achievements mean personal development and the development of an environment in which participants support and encourage each other to deliver excellent results (Dvergsdal and Haga 2013).

Organisational and personal trust may be seen as dealing with different dimensions, the one collective, the other individual. Trust is, despite the distinction between the organisational and the personal, a collective phenomenon. On the one hand, it is a phenomenon that emerges from a collective interpretation (the organisational); on the other hand, it arises from individual characteristics that appear in interpersonal relationships (the personal) (Sørensen et al. 2014). At the same time, building trust represents one way to gain control over the organisation. This duality has to a limited extent been problematised in research around trust (Long and Sitkin 2006).

Trust has been established as a separate research field, and the literature in that field has gradually become significant. Nevertheless, certain areas remain less discussed and developed, including the question of how trust can be cultivated or developed. The research question we are therefore addressing is this: what factors are decisive for developing trust in a temporary team?

\section{Trust in a socio-technical system}

The concept of trust may refer to a psychological state, thereby placing the concept within the psychological discipline:

“Trust is the confidence among team members that their peers' intentions are good, and that there is no reason to be protective or careful around the group. In essence, team-mates must become comfortable with being vulnerable with one another ... A crucial property of trust is that it requires an as-if attitude on the part of the trustor which renders irreducible vulnerability and uncertainty unproblematic" (Lencioni 2002:195).

These definitions of trust include two conditions that recur in several such definitions: having good intentions and being vulnerable. These two conditions are emphasised as crucial to achieving individual and organisational learning (Fonagy and Allison 2014). Fonagy and Allison introduced the concept of "epistemic trust" to capture this learning dimension:

"Epistemic trust - that is, an individual's willingness to consider new knowledge from another person as trustworthy, generalizable and relevant to the self" "(Fonagy and Allison 2014:5).

The intention with team organisation, they argue, is not to delimit performance to the knowledge and insight of specific participants, but to encourage team members to embrace or contribute to other people's absorption of new insights so that new common knowledge can be created. For this to happen, the safety net (the conditions that make participants reserved, defensive and suspicious) has to be lowered or removed so that it does not prevent people from being curious and from accepting and investigating seriously what others are offering. Conversely, it should not prevent the participants from sharing their own knowledge with others.

The concept of trust can also be understood as containing elements of discretion and relational aspects:

"Trust involves good faith and good will: a shared belief that all parties are genuinely working towards some agreed purpose or objective" (Felstead 2009:25). 
As the quotation emphasises, trust involves an element of faith and good will that is discretionary. At the same time, in organisations or projects, much effort is invested to create a common perception that all work is targeted towards a common goal, and that in the effort to achieve these common goals, relationships are generally decisive. Felstead et al. conclude that in order for an organisation to function, three forms of trust are important: habitual, symbolic and community (Felstead 2009). By habitual trust, Felstead el al. understand trust that is about the giving or exercising of judgement being legitimised and validated through real or perceived history and tradition, reliability and solidarity. Symbolic trust is where uncertainty around assessments is validated by moral symbols or ethical values. Community trust is where the parties identify with each other and share a sense of community bonding that is highly emotional.

The concept of trust is also included in a separate organisational-sociological discourse. In this discourse, the concept is interpreted within an organisational framework:

"it is argued that the survival of such [individual] relationships in the face of these inevitable inter-personal problems requires the establishment of inter-organizational trust. Such trust is characterised by community of interest, organisational cultures receptive to external inputs and widespread and continually supplemented knowledge among employees of the status and purpose of collaboration" (Dodgson 1993:77).

In this tradition, the concept is assigned an organisational element that was absent from the psychological discourse. A backdrop of rapid change, in technological, market and customer relations, is used, which makes interorganisational collaboration necessary:

"While this [interpersonal trust] is undoubtedly crucial, this paper argues it is important to examine interorganisational trust. It contends that effective learning between partners depends on a construction of a climate of trust engrained in organisational modes of behaviour, and supported by the belief in the mutual benefits of collaboration throughout the organisation. Only when such inter-organisational trust exits can the partnership continue when inter-personal relationships break down” (Dodgson 1993:78).

Curral and Inkpen have created a model that summarises various relationships between those who trust (Trustors) and those who are trusted (Trustees) (Curral and Inkpen 2006). As stated in the model, both person-to-person relationships (person-person, person-group and person-company) and inter-organisational relationships (groupgroup, group-company and company-company) are included (Figure 1).

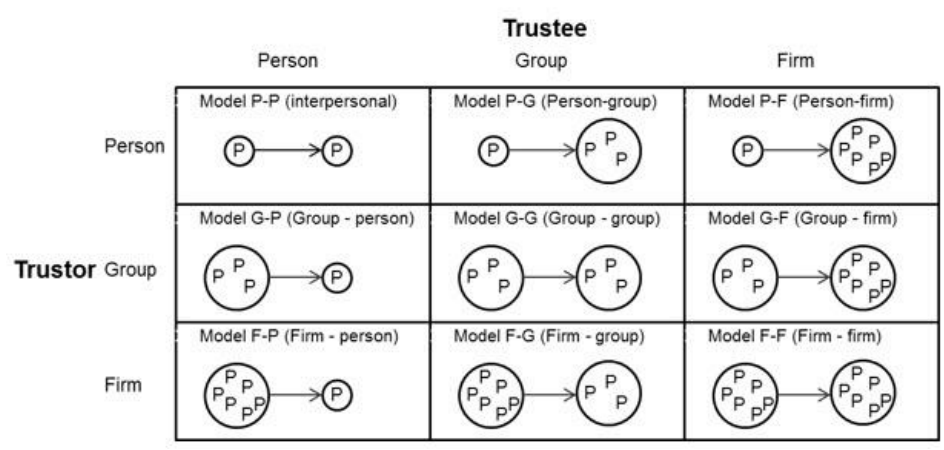

Figure 1. Curral and Inkpen's model of trustor-trustee relationships. Source: Curral and Inkpen 2006. 


\section{E UROPEAN JOURNAL OF W ORKPLACE INNOVATION}

The model illustrates that trust is a phenomenon that must be given attention both individually and organisationally, and between person and organisation. Even trust in inter-organisational relationships, which are otherwise very important for offshore ETO contractors, completely dependent of suppliers as they are, must be put on the agenda in order to increase productivity, improve competitiveness and reduce risk. Trust should therefore not be underestimated as a fundamental premise in a socio-technical system, particularly in terms of redistribution of tasks and responsibilities when introducing new technology and/or reorganising the organisation

How managers integrate trust building and task control is discussed by Long and Sitkin (2006). They note that although the relationship between control and trust is the key to organisational efficiency, the literature is ambiguous on this point. Long and Sitkin developed a model that identifies prominent trust control relationships and clarifies

"how various trust-based and control-based elements are determined, integrated and actuated in the ongoing development of managerial attention and action" (Long and Sitkin 2006:96).

They argue that trust-building and task control activities carried out by the leader affect both how the employees perform the work and the quality of the relationship between manager and employees. At the same time, the managers may benefit from evaluating employee benefits and the degree of conflict between management and employees to assess how efficient the task control is and the extent of the trust the leader enjoys with employees. Nevertheless,

"While recent research has begun to acknowledge the importance of trust and control in facilitating both subordinate task performance and superior-subordinate relationship quality, analyses of how these factors affect future managerial actions is less well understood" (Long and Sitkin 2006:96).

Accordingly, what follows here offers an analysis of how various factors affect the exercise of management.

Building trust is a relational activity between different actors. It may, as we have seen, involve different types of relationships, personal or organisational. The decisive dynamic in a relationship of trust is in all cases between one who trusts (the trustor, or trust giver) and one who trusts in another (the trustee, or trust taker) (Figure 2).

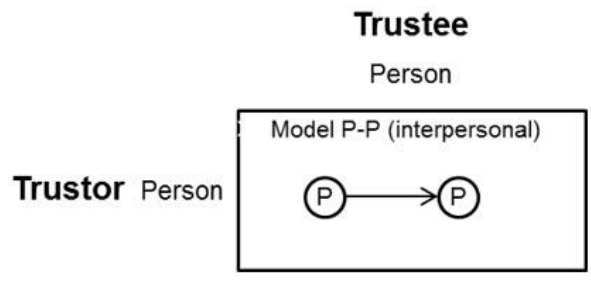

Figure 2. The trustor-trustee relationship.

Figure 2 illustrates the dynamic through an example that involves a personal relationship. In such a situation, there can in principle be a focus from either side: that of the trust giver (who gives) or that of the trust-receiver (who takes): 


\section{E UROPEAN JOURNAL OF W ORKPLACE INNOVATION}

"One learns that crucial dynamics in a trust relationship does not always focus on the trust giver. Paying closer attention to the trust taker and analysing a trust episode by first noting the performance acts the taker adopts in order to motivate the trust giver to make a one-sided advance concession, recast the nature of the exchange involved in the trusting" (Mehra 2008:273).

In order to be maintained, trust relationships must be continuously confirmed:

"One learns to pay closer attention to how trust is re-accomplished: how it is treated continuously as if it were a first moment of trusting. Trust has to be worked on: every move is the first move that recognizes the autonomy of the other and the other's freedom to honour or exploit trust" (Mehra 2008:273).

To strengthen trust relationships practically, the focus must be directed toward both parties in the relationship, and continuous confirmation of trust has to be emphasised. Trust is not something that is established once and for all; it must be continually confirmed.

How, then, is it possible to reinforce trust? Empirical studies have shown that it is more efficient to implement dedicated measures in compressed periods, instead of long-term linear processes where the intention is to build "stone on stone" (Bang 2013):

"Empirical evidence suggests that instead of a frequent assumed linear process of trust development over the history of interaction, trust formation can progress in distinct temporal phases characterized by unique features" (Mehra 2008:277).

The applied theory calls attention to several fundamental conditions for establishing and supporting trust-based operations:

- $\quad$ having confidence in colleagues and managers

- $\quad$ tolerating being vulnerable

- community bonding, symbolic and habitual trust

- the inter-organisational concept of trust, not only the personal concept

- a common understanding of the relation between trust and control.

The theory also calls attention to how to create trust in an organisation, particularly in terms of the following considerations:

- Trust relationships are dependent on all actors being seen and receiving attention.

- Maintaining a relationship of trust requires constant attention from the participating actors.

- A temporal phase with unique features is as efficient as a linear process of trust development.

\section{Method}

Creating team processes in project teams is not a self-evident element in project implementation; it will largely be governed by the project manager and his/her preferences. For project managers, it is about control of the project and deciding what is the most appropriate way to achieve this control, i.e., finding the right balance between the exercise of power and trust control. 
We, as researchers, have experience from team processes in various projects and, on the basis of these experiences, we have developed an approach that is used and discussed below. The approach may be understood as a stepwise process:

- $\quad$ mapping of team and team performance

- establishment a common fundamental understanding for trust-based interaction

- developing relevant agendas for workshops, both for team interaction and for operations

- individual coaching between workshops

- observation with immediate response in workshops

- individual reflective interviews towards the end of the project.

Throughout the various team processes we have been part of, we have experienced defects and failures that have caused necessary transformations of the approach, and so on. This is purely a consequence of the research design. At the same time, a review of the literature has provided relevant new perspectives, especially regarding the balance between control and trust (Sørhaug 1996).

To understand how team processes are constructed and how they function as trust-building nodes for teams designed to carry out time-limited projects, research may be part of the knowledge building process (Greenwood and Levin 2007). By focusing on the practical situations, we have encountered in the construction and implementation of team processes, we argue that the role of research must be based on the participants' needs, which vary. Despite the variation, it is possible to extract a general understanding from the processes, which can then be presented to the participants. From shared reflection on the researchers' findings, it is possible to obtain new knowledge. For the researchers, the ability to register and integrate divergent interests and many perspectives (and, based on these, input from generalised knowledge) is thus decisive. In such a process, interaction with participants is crucial for shaping new knowledge. The feedback from participants on the researchers' findings and shared reflection on the findings is the engine that drives new knowledge. It requires an open and curious approach from both researchers and participants.

This approach is necessary simply because neither the implementation of a successful team process nor the establishment of new knowledge can be achieved if different actors, who come in with different perceptions of the current situation, are unable to establish a common basis for joint work. For this reason, the researchers have to adopt an open role, and it is inevitably the researcher's task to create situations that give access to areas he or she has seen into position, in order to contribute to the implementation of the phenomenon that is to be studied, and at the same time contribute to knowledge building around the phenomenon.

In our case, feedback from the participants was also collected through formal interviews. The project led by the management team was time-limited, and when the assignment was completed, the participants were interviewed about their experience with the team development process. The participants' reactions and reflexes during the process, as well as their more retrospective assessments and reflections, thus form the basis for this article.

To sum up the main elements of the approach used, the researchers carried out the following tasks:

1. designed the team process that was used and that guided the team through the process

2. conducted a number of formal interviews after the assignment was completed

3. summarised the participants' experiences and drew conclusions from these in this paper. 
These steps were carried out in close interaction with the actors involved. Fundamentally, the aim of the company and that of the researchers were at least partly identical: to identify basic principles for building trust in management teams. Of course, the main aim of the company project manager was to get his team to work well, thereby reducing the need for control. The reflexive process of identifying such principles thus included the members of the management team. Their involvement was important to ensure consistency and reliability of results. The chosen research approach was also designed to ensure valid results, as these were continuously the subject of shared reflection.

Thus, the experiences set out below from the implementation of these dedicated measures in a project team will be reviewed, covering both what was done and what experiences the participants were left with after the project was completed. Consequently, this is not a study where a phenomenon is studied from the outside. We as researchers participated as actors in the field, and we not only participated but to a large extent directed what was happening in the field (Greenwood and Levin 2007).

\section{The team process: main elements}

In this section we will present a team process carried out in a specific project: what was actually done, what the intentions were and what the results were of the various activities. Activities initiated may have multiple purposes. We concentrate on activities and practices that can shed light on how trust is strengthened, maintained and, not least, maintained when the conversation focuses on topics which one or more members of the team have a demanding relationship with (Table 1).

Table 1. Main elements of the team process and their effect on trust.

\begin{tabular}{|l|l|l|l|}
\hline Activity & Intention & Technique & Effect on trust \\
\hline $\begin{array}{l}\text { Mapping the } \\
\text { present } \\
\text { situation }\end{array}$ & $\begin{array}{l}\text { Introductory sale } \\
\text { Attention } \\
\text { Ownership } \\
\text { Trust consultant vs } \\
\text { team }\end{array}$ & $\begin{array}{l}\text { Individual conversation } \\
\text { Open questions } \\
\text { Describe rather than characterise }\end{array}$ & $\begin{array}{l}\text { Engagement } \\
\text { Concerns made explicit }\end{array}$ \\
\hline $\begin{array}{l}\text { Adjusting to } \\
\text { the current } \\
\text { situation }\end{array}$ & $\begin{array}{l}\text { Adaption to situation } \\
\text { and needs } \\
\text { Make sure the project } \\
\text { manager has support } \\
\text { and a place to } \\
\text { discuss dilemmas }\end{array}$ & $\begin{array}{l}\text { Project manager's (or HR's) } \\
\text { description of needs } \\
\text { Coaching conversation about needs } \\
\text { Researcher's observations } \\
\text { Teaching specifically adapted to the } \\
\text { situation }\end{array}$ & $\begin{array}{l}\text { Strengthening of trust between project } \\
\text { manager and researcher } \\
\text { A well-liked leader learned how to support } \\
\text { his team even more }\end{array}$ \\
\hline $\begin{array}{l}\text { Conducting } \\
\text { workshops }\end{array}$ & $\begin{array}{l}\text { Change the team's } \\
\text { position strategically } \\
\text { and as a team }\end{array}$ & $\begin{array}{l}\text { Two levels in parallel: (1) specific } \\
\text { dilemmas and (2) insight and } \\
\text { interaction skills }\end{array}$ & $\begin{array}{l}\text { Dialogue increased insight and changed } \\
\text { fixed positions, individually and as a team }\end{array}$ \\
\hline $\begin{array}{l}\text { Individual } \\
\text { coaching }\end{array}$ & $\begin{array}{l}\text { Move from insights } \\
\text { presented in } \\
\text { workshop to daily } \\
\text { operational practice }\end{array}$ & $\begin{array}{l}\text { Gestalt engraved method } \\
\text { Strengthen trust between } \\
\text { coach/researcher and coachee } \\
\text { Model a trust-based interaction } \\
\text { Individual talks after each team } \\
\text { workshop }\end{array}$ & $\begin{array}{l}\text { Alternation between team intervention and } \\
\text { individual interventions gave observable } \\
\text { changes } \\
\text { Motivation for further learning }\end{array}$ \\
\hline
\end{tabular}




\section{Mapping the current situation}

As a starting point for the process, a mapping of the team situation was carried out. Individual interviews were conducted, and statements were written down, reflecting as far as possible what the individual had said. The principle that everyone should represent themselves was made explicit at this early stage.

The report that was prepared consisted of a foil kit containing chapters with both strategic and real team-oriented topics. In the chapters, the team used their own statements, although the topic was summarised in the researchers' words. The preference was for the form to be descriptive rather than characterising and categorising (Dvergsdal 2014). The report then summarised, as the researchers saw it, which topics were regarded as being of particular importance and which should be addressed. The presentation ended with recommendations related to each main theme/topic.

In this way, we obtained a description of the situation in and around the team and in the team's own words (Dvergsdal 2014). When this report was presented to the team, the participants were given time to consider how they perceived the situation together, and to take this insight into common ownership. The principle of focusing on the experience of those who participated was used (ref. theory chapter on the trustor-trustee relationship).

\section{Workshop planning}

The agenda for each workshop should be relevant to the team's current situation; that is, it should help deal with relationships internal to the team, as well as respond to the expectations in the environment. The agenda for the workshops was based on the team's situation and was not conceptually conditional. However, the planning and implementation method was fixed.

At the first workshop, agreeing on fundamental assumptions was the most important point on the agenda: what characterises the starting point of the team, what level of integration the management needs to work at, what requirements and expectations are set by the participants, and what support is needed or expected from the other team members. The basic structures in the team must be in place. If these are present, the experience itself will provide a powerful stimulus to act as a team, between the workshops as well as during them. That means working exemplarily, with each activity illustrating its own purpose. At the same time, the process must be time-efficient, with each activity emphasising its purpose in both content and form.

In terms of planning the next steps (the four workshops), the agenda was less obvious. It was made clear that workshops with purely psychological or strategic topics were not desirable. The strategic situation could be taken as a starting point, but then the team and the individuals should be focused on specific questions. In what way was the team challenged by the present situation? What was it important and necessary to recognise, train, change or develop? Finding the right agenda was work that had to be done close to each workshop. As researchers, we often take models and learning principles as a starting point (ref. theory section), whereas in this case the project demanded a tailored agenda adapted to the project situation.

Such a situation-based agenda required interaction between the project manager and the researchers, but it was sometimes challenging to achieve this. The project manager occasionally failed to find time to sit down with us and reflect on what was needed. When we were coming close to the next workshop, it was hard to find time for a planning meeting. On one occasion, when we finally reached him he was about to board a plane in Eastern Europe and said this: 
"We work individually now, and not as a team. It's noticeable for people working close to us and this way of working will not give us desirable results. If we continue in the same direction, we will not achieve our targets. Are you able to make us a team again? Sorry, but I have to leave. Bye."

We told the project manager that he had to start the next workshop by repeating what he had told us as he boarded the flight. That message made it possible to focus on how the divergent working methods were affecting the team. The discussions and conclusions within the team meant that several individual actions were stopped, and certain other actions were jointly decided on and implemented.

The agenda for each workshop was based on observations, summaries from coaching sessions and input from the project manager, and it was the subject of in-depth conversations between the project manager and researchers. The dialogue was holistic, reality-oriented, purposeful and clearly built trust between the project manager and the researchers. However, the project manager always had the final say.

\section{First workshop: a prioritised agenda based on thorough mapping}

The workshop began with the project manager thoroughly, concisely and clearly talking about the need to build the team. We, as researchers, then went through how we had planned to work and why. For us, it was important to give the participants insight into how we worked and, if possible, to create engagement within the team to participate actively in developing the team. We stated that we would like to see involvement and participation in establishing a working method in which it was natural to discuss how the team and the individual members, through internal interaction, could best solve their strategic challenges. However, in order to achieve this, each individual team member had to accept being challenged, albeit in a safe and supportive environment. We, as researchers, did not want to give the participants the impression that we considered ourselves to be external experts with knowledge and concepts that would simply be rolled out.

After that, each team member introduced her-/himself. Most team members opened up when talking about their own situation and what they wanted out of the process. We were aware that this initial phase could mean a lot to the participants, and therefore we emphasised it and gave it a generous amount of time. When the researchers went through the survey report that they had prepared, the point of departure was quickly agreed, but no more. It was possible to see and hear that people had moved closer together during the introduction; they were reflecting in open and personal ways and giving each other feedback.

The next part of the workshop considered whether we needed to be a team and why, and this created much engagement. Someone went so far as to say that they needed their colleagues to succeed. Powerful statements were made, for example that we cannot succeed without agreeing on strategy and problem-solving methodology in the project, and that the company may be in danger of being closed down if we do not succeed. It was the most experienced team members who spoke. The relatively new people at this level in the organisation kept quiet. The project manager concluded by telling the participants that he expected them to work closely together as a team.

Clarifying the sole responsibility of each team member in detail is important, and this was therefore the focus during the reviews of the roles of individual team members. Each team member was asked to reflect on their key management and governing challenges over the next six months. This was not to be considered in isolation from who they were and their expertise but was to be looked at in conjunction with how these tasks would challenge them as a person. Each team member was asked to reflect on what it was necessary to change, what procedures should be changed or adjusted and what support was needed from other areas or other people. When left alone, the team members were asked to write down their reflections. These reflections were later presented to the rest of the team, and the team members received feedback on these reflections. The researchers facilitated this process, which was strictly structured by setting requirements for the quality of the presentation and the feedback. We required 
substantial feedback that built on facts and was thoughtful about whether the issues being addressed were essential. The researchers stated that they would intervene, if necessary, for the feedback process to be experienced as useful. We encouraged a responsible process that was characterised not by reactive or distinctive interests but by shared goals and a proactive stance.

In this round, nothing unexpected occurred. Several team members were challenged on tasks and ways to execute them, and the role of the team leader was particularly striking. The whole team expressed great respect for his honour, integrity and diligence in ensuring that the team would succeed. Although reviewing and giving feedback to all team members was time-consuming, the entire team focused on the process, without exception. Participants were encouraged to emphasise what they regarded as important issues and to talk openly about their complexity (Dvergsdal 2014). They all managed to do that, and thus the conversation was focused and clear. At the same time, they were encouraged to confirm each other's views where that was justified.

The conversation was just as focused towards the end of the round as at the beginning. Those who had the group's attention showed, through verbal and non-verbal signals, that the content of the conversation was important to them. It resulted in statements such as the following:

"it means a lot to me that you confirm that I should now improve the relationship to supplier X" (Interview 1).

It seemed that genuine confirmations opened up good reflections on real and important challenges. The support was obvious, but both expectations and challenges were addressed. The genuine nature of the support seemed to make people more proactive, and they responded to challenges in a clear and nuanced manner. There was almost no explaining away of problems or blaming of other people; instead, there was a lot of serious consideration as to how to move forward and succeed.

It was important that team members should understand the feedback and would be able to sort and understand it immediately. No one should leave the team meeting with an unclear understanding of the content of the feedback. For a good feedback process, it is essential that the feedback be based on observations and/or other facts. At the same time, the feedback must take a balanced form. Where this balance was lacking, the researchers intervened and corrected, until the person being focused on expressed that things had fallen into place. Some participants were unfamiliar with discussing and analysing their own leadership roles openly with many people listening.

In a round of brief comments on what they took away from the first seminar, the participants expressed a consensus that they now felt like part of a team; in other words, something had changed for the better in the course of the seminar.

\section{Individual coaching}

Everyone in the team was offered and received individual coaching from the researchers. We choose two examples to include here. The first example involves a highly experienced and recognised professional who, in his own field, apparently operated without being burdened by a managerial role. We will call him Tor. The other example involves a relatively new leader, who is quiet and whom few participants knew from previous projects. We will call him Nils.

Tor was responsible for the project's largest subcontracting contract, but the communication with the supplier was working poorly. Tor, with his professional background, had focused on formal and professional communication with the subcontractor. The result was that the supplier heard from Tor every time something seemed to be wrong, and, as a specialist in the field, Tor was often correct. The supplier was thus pushed into a pattern of responding to 
professional corrections from Tor and only to a minor extent focused on correcting errors upstream so that they could be dealt with before delivery. In order for the vendor to be able to change this pattern, Tor had to act in a different way; instead of correcting the supplier, he would have to encourage the supplier to improve his internal process. Tor had to change from being a specialist to being a leader.

The first step was to focus on building closer relationships with the supplier, through more informal and dialogueoriented communication. Tor started by going on morning walks around the office where personnel from the relevant supplier were located. He was then able to sit down with the supplier and help find good professional solutions. In this informal setting, Tor's warmth and humour came to the fore and contributed substantially to improving the relationship with the supplier. This was appreciated to the extent that if he missed going on his rounds, other people asked for him and he quickly returned to the new routine. During later coaching, Tor reflected on the fact that it had taken him to the age of 50 before he understood the need to use skills other than strictly specialist ones to get close to the supplier.

With Nils, there was a different dynamic in the coaching process. It turned out that Nils had management experience from his previous workplace, both of a general and more specialist nature. However, lacking personal relationships and experience in the new workplace, it was hard for him to become fully integrated in the team. His quiet personality did not help, as he often appeared taciturn and difficult to approach. Consequently, the coaching with Nils focused on whether he could become more open; he had to take action and show more of himself to the team. Nils was subsequently more active in his rounds and with feedback in the workshops. He signed up to take responsibility for joint tasks in the team. The whole process supported him in becoming able to take responsibility and benefit from people's expertise, and to communicate more openly. The development of both Nils and Thor was visible to the other team members, and it inspired the further development of the team.

\section{Fundamental principles for building trust}

We have identified six fundamental principles that underlie the scheme outlined above and which

- $\quad$ focus on both the trustee and the trustor

- $\quad$ may be used on measures that are limited both in time and quantity.

We briefly present each of these principles below.

\section{An agenda that is focused, relevant and prioritised}

"Everyone was open in both the first and next rounds. This was a nice way to check out expectations and their impact on others. However, the process was conditioned by the way the rounds were carried out: co-ordinated and under strict control" (Interview 5).

Many approaches offer generous time and theme-related group work to try to speed up the development process. We, on the other hand, are interested in investigating whether a tight agenda with selected topics and short periods of group work with clear expectations for delivery can contribute to a rapid progression. We believe that a distinct framework stimulates creative thinking and establishes ownership of the outcome of the group work. The participants understand intuitively the idea behind the tasks given, and they are able to understand their team's role as part of a totality and why the tasks are being addressed (Zinker 1978). 
Operating in such a setting, with a tight agenda and clear delivery expectations from the participants, is a discipline. The participants quickly understand that a regime has been established to regulate time spent in meetings and to encourage timely individual delivery. Experiencing clarity on such issues and on what such discipline does with the quality of discussions, possible solutions and achievable results is convincing and strengthens the support for the project and the approach. Positive experiences in the management team make the transfer of such a regime to other parts of the organisation both possible and desirable.

\section{A model of excellent co-operation}

"The project was characterised by demanding challenges, and a lot to do. As well we lacked knowledge. In this setting the project manager was exemplary" (Interview 6).

Getting more value out of the co-operation within a management team is about understanding human behaviour, particularly when the aim is to create something beyond the present moment. This includes being able to establish effective ways to work together, both within and outside meetings. In addition, team members are expected to acquire teamwork skills quickly, preferably during a couple of one-day workshops. However, a role model in the team will illustrate better than anything else what is expected. It is not necessary to copy the role model; its importance is that it allows a person to see the direction that he/she might take. In addition, role-learning takes place continuously, regardless of whether this is intentional. The more the project manager and the researchers are conscious of "delivering" trust and acting in a team-oriented way, the more this will affect the context. Conversely, if the researchers are reserved, focus on threats more than trust, and are able to operate at a superficial level only, their teaching about key elements in team building will have a reduced effect.

Initiating trust building is a management responsibility. In order to quickly develop a relationship of trust with team members, the project manager must act to inspire trust and signal strongly that he/she wants the others in the team to act in the same way. Communicating the project manager's vulnerability and uncertainty may enable other team members to do the same. It may be frightening for the project manager to experience the openness of other members of the team about uncertainty, risk and lack of competence. On the other hand, it provides security for the project manager that all known risks and problems in the organisation will be made public and discussed. As long as the conditions are known, it is possible to handle them; where conditions are hidden, it is much more difficult to handle them effectively.

\section{A climate that promotes learning and being seen}

"As a consequence of the rounds around the table, communication between us became easier, and not only in the workshops but generally. We thought differently about the way we approached each other and we became more aware of the way we did it. Suddenly a huge desire to succeed with the project, the whole project, appeared" (Interview 2).

"The rounds around the table gave an overview and overall picture" (Interview 3).

"Very good to know what others think is important. I would say it's a 'agile way to reach the target'. It was exciting to listen to the others - get to know new ones" (Interview 6).

A number of educational researchers have stated that we learn most from the teacher who sees us (Grendestad 1981). In the mental health services, research has shown that the result of treatment is better if there is a trusting 
relationship between helpers and help seekers: "our job is to make us trustworthy". Why should this be significantly different in a project management team? We believe that the climate in which one has started developing the project management team is crucial for the result.

On the one hand, being seen and being given space in meeting arenas makes the individual feel that he/she belongs, is accepted and is worth listening to. A workplace where employees experience this is often regarded as an attractive workplace: that is how many employees would like to see their workplace. It makes them dare to open up more than they would in other settings; since their ideas and suggestions are taken seriously, self-esteem and security are reinforced. On the other hand, such behaviour leads to more transparency, which reduces what can be kept private. If an individual face a challenge or is in doubt about anything, he/she will air it in the team, because that is possible. Increasing transparency will, from a controller point of departure, reduce uncertainty: as soon as risk occurs, it will be aired in the team without barriers.

\section{An investigative attitude}

"These rounds were incredibly important. One could test out if the deliveries were in according to the other team members' expectations. When one team member was presenting, the others could reflect upon their possible contribution to the presenter. Rather positive contributions than making demands to all the others. This allowed us to share tasks and responsibility for succeeding with the totality" (Interview 7).

"It was important that the check-out was done in plenary sessions: simply more efficient. It created collegial team support. We were influenced by each other there and then" (Interview 8).

We believe that focusing on achievements, as opposed to having an understanding mindset, may be detrimental for building trust. The performance element will always be relevant, but when the performance element becomes essential for the facilitator, project manager and team members, we believe it weakens some of the foundations for trust. Trust partly comes from doubt and curiosity: "I don't know everything; what have you seen?" To display how clever you are and that you are cleverer than your colleagues does not necessarily build deep and lasting trust. If the start of an event is marked by such behaviour, you will almost never get the chance to achieve close relationships with others. It is therefore essential to move away from a relationship based on "from me to you communication" and towards a mutual relationship based on "me-you communication" (Buber 1923). It helps if the project manager and or the researcher say something about this:

"Be investigative, see if you can spot conditions you have not thought of before, but that others have seen here.

Such an effort really contributes to what we are looking for to build the team" (Interview 4).

To explicitly build this value as a norm will help the process move in a learning direction. At the same time, it will build trust in the team, and in the project manager, that will make it possible to be investigative and forthright without being regarded as an enemy. Such an approach is a significant contribution to reducing risk. By acting as "devil's advocate" with team members who have a different point of view, and by asking relevant questions about your suggestions, you are enabled to look at situations through new eyes and make necessary adjustments. In many teams, acting in this way will be seen as an attack; therefore, team members will be reluctant to do it in case of reprisals. Nevertheless, this form of work improves the quality of decisions and dispositions while maintaining control of the organisation. 


\section{E UROPEAN JOURNAL OF W ORKPLACE INNOVATION}

\section{Accountable and complete communication}

"Being able to criticise each other without hurting each other: incredibly important! We understood that demanding feedback was not meant as an offense, but to improve the process. This was generally the way we experienced the team process" (Interview 3).

The word "authentic" is powerful and must be used with care. Sometimes you may get the impression that if just a few words are authentic and honest, they are worth saying, regardless of how they are said. On the other hand, we believe that the way in which a message is presented and the intention behind the message are decisive. They must emerge from the context that the message is posted in, which is supposed to be an attempt to help the recipient.

It is important to communicate that accepting feedback makes one a trustee and that giving feedback makes one a trustor. The process of switching between the roles of trustee and trustor is itself a strength of our approach. By making themselves vulnerable in giving and receiving feedback as recipients of trust, and by giving trust within a responsible framework, participants feel that others wish them well, and this builds trust.

Fundamental to the relationship between the team members is communicating that criticism is allowed without the receiver perceiving the message as an attack; criticism is to be perceived as positive input to improve the work that is being done in the area for which you are responsible. Criticism is meant to support and help you; the critics wish you well. When the message behind the criticism has been perceived in this way, greater transparency and openness are facilitated, thus achieving a better climate in the team and helping the project manager and the project team to better control the project.

\section{Representing oneself}

"It was tiring to be in focus, unfamiliar to me, but afterwards when I had checked out my way of thinking about my contribution and received constructive feedback, I had a very good feeling" (Interview 4).

"We learned that something positive came out of it. This gave positive expectations for the future." (Interview 5).

"When others were in focus and I could give feedback, it was easier" (Interview 7).

"The first time we sat down. The next few times we stood upright, with our own presentation on the wall. That was a tough exposure, but it became useful" (Interview 7).

Representing one's own experience when it is needed is the individual's own responsibility. In a team process, it promotes order and safety to make it clear that this is the case and that it is expected of the participants. It is worth supporting individuals to do this when necessary. On the other hand, one must follow up and intervene if there is uncertainty about the ownership of a genuine "own" experience. This is a task that the researcher owns.

Bringing the expectation that participants will draw on their previous experience in assessments and in discussions improves the quality control of decisions and priorities. Information about how different challenges may have been solved in other projects is excellent input for how the project team should meet the current challenges. This principle increases the solution space for the project team and the project, thus enabling project management to handle challenges more efficiently and with better results, thus reducing the overall risk in the project. 


\section{Interdependence of the principles}

Table 2 provides a summary of the principles.

Table 2. The six principles and their effects on trust and control.

\begin{tabular}{|c|c|c|c|}
\hline Principle & Reason to initiate & Effect on trust & Effect on control \\
\hline $\begin{array}{l}\text { An agenda that is } \\
\text { focused, } \\
\text { relevant and } \\
\text { prioritised }\end{array}$ & $\begin{array}{l}\text { Fast progress, evident } \\
\text { delivery, innovative, } \\
\text { understandable frames }\end{array}$ & $\begin{array}{l}\text { Safety, higher expectations } \\
\text { and quality }\end{array}$ & Discipline \\
\hline $\begin{array}{l}\text { A model of } \\
\text { excellent co- } \\
\text { operation } \\
\end{array}$ & $\begin{array}{l}\text { Highlighting the type of } \\
\text { behaviour that is desired in } \\
\text { the project }\end{array}$ & $\begin{array}{l}\text { Making vulnerability and } \\
\text { uncertainty acceptable }\end{array}$ & $\begin{array}{l}\text { Problems in the organisation } \\
\text { are raised and discussed }\end{array}$ \\
\hline $\begin{array}{l}\text { A climate that } \\
\text { promotes } \\
\text { learning and } \\
\text { being seen }\end{array}$ & $\begin{array}{l}\text { You learn best when you are } \\
\text { seen }\end{array}$ & $\begin{array}{l}\text { Feeling that one belongs, is } \\
\text { accepted and is being } \\
\text { listened to }\end{array}$ & $\begin{array}{l}\text { Increased openness: people } \\
\text { keep less to themselves }\end{array}$ \\
\hline $\begin{array}{l}\text { An investigative } \\
\text { attitude }\end{array}$ & $\begin{array}{l}\text { Focusing on understanding } \\
\text { rather than performance }\end{array}$ & $\begin{array}{l}\text { Permission to explore, ask } \\
\text { questions and reflect: no } \\
\text { question is stupid }\end{array}$ & Increased transparency \\
\hline $\begin{array}{l}\text { Accountable and } \\
\text { complete } \\
\text { communication }\end{array}$ & $\begin{array}{l}\text { Focusing on giving and } \\
\text { accepting building } \\
\text { criticism }\end{array}$ & $\begin{array}{l}\text { Criticism is perceived as a } \\
\text { desire to support and help }\end{array}$ & Increased transparency \\
\hline $\begin{array}{l}\text { Representing } \\
\text { oneself }\end{array}$ & $\begin{array}{l}\text { Strengthening self- } \\
\text { confidence among team } \\
\text { members }\end{array}$ & $\begin{array}{l}\text { Contributing experience } \\
\text { strengthens the team }\end{array}$ & $\begin{array}{l}\text { Previous experiences used to } \\
\text { provide solutions and reduce } \\
\text { risk }\end{array}$ \\
\hline
\end{tabular}

The principles call attention to the attitudes and behaviour of the participants in the team. The participants undergo a harsh learning process during the short workshops: it is not possible to hide behind other people. Individuals must expose themselves, and they are expected to participate actively in the workshops, in management meetings and generally in the team, drawing on their expertise and experience to do so. At the same time, they are expected to be supportive, exploratory and transparent. Signing out and leaving other team members to take responsibility for their own business without getting involved is not acceptable. It is the overall competence, experience and human capacity in the team that will solve the team's ongoing challenges.

Thus, in order to develop trust within a project team, it is not possible to choose principles arbitrarily: the elements set out here form a totality. Fundamental to the approach is the positive desire for individual project team members to function and work well in their positions and to deliver according to expectations in the area which they are responsible. To achieve this, we argue on the basis of the case study that all principles must be present and in use.

If the project manager is to achieve good management and control over the project implementation, a necessary step is to establish a trusting relationship among the project management team members. As a consequence of the trust relationship being established, the following will be achievable: 


\section{E UROPEAN JOURNAL OF W ORKPLACE INNOVATION}

- control through transparency

- the creation of a joint project team member community

- a common desire on the part of all team members to contribute to the success of their colleagues.

The principles were thus put into practice with the intention of improving the interpersonal relations within a project management team. One of the research questions raised in the introduction was whether such an approach allows for reduced control measures. The approach is built around open communication, brutally honest feedback, and mutual support and desire to do good to each other. Throughout the project period, the team participants experienced that the internal working environment in the project team changed in a direction where they felt less and less of a need to embellish reality in order to avoid uncomfortable questions from colleagues and managers. Raising issues early in order to seek help from the team became the new way of working. However, improved management steering capability and control are also effects of this approach. Control is not only achieved through a large, rigid control system: good governance and control may be achieved through a conscious focus on relationship building and interpersonal skills. Experiencing vulnerability, humility and joy in the success of others reveals fundamental learning, which both enhances the quality of governance and gives better control. Trust-based management is the key.

Taken together, the principles lay the foundation for the development of trust in a team and for indirectly improved control and steering capability. In this case, they were applied to a management team, but they are equally relevant to teams in general. The case focuses on interpersonal trust, and to a lesser extent on organisational trust. However, it is difficult to imagine that it would be possible to construct isolated nodes where trust-based management is developed, unless the company environment is conducive to this. In order to increase the efficiency of projects in the company in general, it is clearly important to be aware of the connection between organisational and interpersonal trust and to develop them so that they support each other.

The case raises the issue of problematising trust and control in socio-technical design in general. Clearly, trust and control are important in organisational design and for operations, particularly where the implementation and use of new technology is concerned. New technology will open up new forms of interaction and communication based largely on trust. Carl Pava was quick to anticipate such developments, especially in non-routinised jobs (Pava 1983, Austrom and Ordowich 2018). In non-routine knowledge work, deliberations form collectively built frameworks that create clarity for communicators without sacrificing complexity. Deliberations are performed to illuminate problematic issues, innovation tasks etc. and may occur in different forums or settings. Thus, Pava left behind the unilateral approach characteristic of classic STSD in terms of self-managed teams and their interchangeable skills.

In the operations of ETO contractors, continuous deliberations between different actors are a common way of illuminating problems and challenges, and such ways of handling issues are becoming ever more popular. However, such methods can only be used where there is genuine trust; individual and organisational trust are fundamental. Focusing on trust and control in the implementation of new technology and work organisations therefore seems inevitable for the success of restructuring processes. 


\section{E UROPEAN JOURNAL OF W ORK P L A C E IN N O V A T I ON}

\section{Conclusion}

From a review of interviews with participants in a construction project management team and experiences from the development process undergone by the case team, we have identified six key principles for developing trust in a team. This is not a list of principles to pick and choose from; the principles are mutually interdependent, and all six must therefore be adopted together. Neither is there any direct link between increased trust in a team and reduced control measures; a conscious choice to reduce control measures must follow the establishment of increased trust within the team. The principles were developed within a management team in a temporary construction project; however, they may also be applicable for implementation in more stable production teams or in teams of other types.

\section{References}

Austrom D., \& Ordowich C. (2018). "Calvin Pava. Sociotechnical System Design for the 'Digital Coal Mines." In D. Szabla, W. Pasmore, M. Barnes, \& A. Gipson (Eds.), The Palgrave Handbook of Organizational Change Thinkers (pp. 1-31). Cham, Palgrave Macmillan.

Bang H. (2013). “Organisasjonskultur: En begrepsavklaring." Tidsskrift for Norsk Psykologforening 50.42013 Pp 326-336.

Barney J.B., \& Hansen M.H. (1994). "Trustworthiness as a source for competitive advantage." Strategic Management Journal 151994 Pp 175-190.

Buber M. (1923). Ich und du. Leipzig, Insel Verlag.

Curral C., \& Inkpen A.C. (2006). "On the complexity of organizational trust: a multi-level co-evolutionary perspective and guidelines for future research." In R. Bachmann \& A. Zaheer (Eds.), The Handbook of Trust Research Pp 235-246. Cheltenham, Edward Elgar.

Dodgson M. (1993). “Learning, trust and technological collaboration.” Human Relations 46.11993 Pp 77-95.

Dvergsdal D. (2014). Expanding Your Leadership: A Journey Towards Building Character. Oslo: Abstrakt Forlag.

Dvergsdal D., \& Haga T. (2013). "Utvikling av team i tidsavgrensede prosjekter: Verdifull investering eller bortkastet tid?" In H. Chr. Garmann Johnsen \& Ø. Pålshaugen (Eds.), Hva er innovasjon? Perspektiver i norsk innovasjonforskning. Oslo, CappelenDamm.

Felstead A., Fuller F., Jewson N., \& Unwin L. (Eds.) (2009). Improving Working as Learning. Routledge, London.

Fonagy P., \& Allison E. (2014). "The role of mentalizing and epistemic trust in the therapeutic relationship." Psychotherapy 53.3 $2014 \mathrm{Pp} 372-380$. The reference made in the text is from the pre-print version of this paper accepted for publication (February 2014). The page numbering in the pre-print text does not correspond to the page numbering in the final text

Greenwood D., \& Levin M. (2007). Introduction to Action Research: Social Research for Social Change. Sage.

Grendestad N.M. (1981). Å lare er å oppdage. Oslo, Didakta. 


\section{E UROPEAN JOURNAL OF W ORKPLACE INNOVATION}

Lencioni P.M. (2002). The Five Dysfunctions of a Team. San Francisco, John Wiley \& Sons.

Long C.P., \& Sitkin S.B. (2006). "Trust in the balance: how managers integrate trust-building and task control." In R. Bachmann \& A. Zaheer (Eds.), The Handbook of Trust Research Pp 87-106. Cheltenham, Edward Elgar.

Mehra A. (2008). "Handbook of Trust Research: Review.” Academy of Management Review 33.12008 Pp 271272.

Pava C. (1983). Managing New Office Technology: An Organizational Strategy. New York: Free Press.

Sørensen O.H., Hasle P., \& Madsen C.U. (2014). "Trust, performance and well-being in Nordic working life and management research." In T. Isidorsson (Ed.), The 7th Nordic Working Life Conference: Threats and Possibilities Facing Nordic Working Life. Gothenburg.

Sørhaug T. (1996). Om ledelse: Makt og tillit i moderne organisering. Oslo, Universitetsforlaget.

Zinker J. (1978). Creative Processes

\section{About the authors:}

Dagrun Dvergsdal, MA, founder and CEO of Dvergsdal Consulting, specializing in development of leaders and top management teams. Practical and research perspective is expansion of competence towards character growth. Building on trust is a cornerstone in her work with teams. Published a book: "Expanding your Leadership."

Trond Haga, PhD, is Senior Manager at Kvaerner, Norway. Research interests include network cooperation, organization, training, collaborative industrial relations, action research, trust and sociotechnical systems theory. He has published in other journals and anthologies. 